\title{
Оценка минерального состава природных вод кондукто-стохастическим методом
}

Б.Ф.Сулайман, В.Ф.Николаев, д.Х.Н., Р.Б.Султанова, К.Х.Н., Казанский национальный исследовательский технологический университет, Казань

Г.Ш.Скворцова, К.-Ф.М.н. Казанский (Приволжский) федеральный университет, Казань bassel.sulaiman@mail.ru

\author{
УДК 543.3; 681.785.2; 531.756; 543.555; 556.314 \\ Статья поступила в редакцию 23.07.2019 \\ Статья принята к публикации 15.09.2019
}

\begin{abstract}
Предложен кондукто-стохастический подход к оценке состава природных вод по основным ионам $\left(\mathrm{Ca}^{2+}, \mathrm{Na}^{+} / \mathrm{K}^{+}, \mathrm{Mg}^{2+}, \mathrm{HCO}_{3}^{-}, \mathrm{SO}_{4}^{2-}, \mathrm{Cl}^{-}\right)$, основанный на измерении аналитических сигналов интегральных физических методов - кондуктометрии, рефрактометрии и денсиметрии. На основе статистического анализа массива эмпирической информации по 500 образцам природных вод получено 15 стохастических уравнений, диктуемых парными и групповыми межионными корреляциями, меняющимися с ростом удельной электропроводности. Оценку ионного состава проводили на основе решения методом взвешенных наименьших квадратов системы стохастических уравнений при заданной экспериментальной удельной электропроводности образца. В перспективе разрабатываемый метод может найти применение в рутинных полевых/портативных гидрохимических кондукто-рефракто-денсиметрических экспресс-анализаторах, погружных/глубинных зондах и в мониторинговых буях.
\end{abstract}

\section{ВВЕДЕНИЕ}

Существующий комплекс лабораторных аналитических методов (капиллярный электрофорез, ионная хроматография, титриметрические методы) и приборов [1-8] позволяет с достаточно высокой точностью определять содержание как макро-, так и микроионных компонентов природных вод. В то же время портативные гидрохимические анализаторы, мониторинговые буи и глубинные зонды не могут оценивать состав вод по основным ионам из-за сложности миниатюризации приборного обеспечения аналитических методов контроля качества вод, рекомендованных действующими стандартами. Возможности портативных анализаторов, как правило, ограничиваются отслеживанием таких химических и физико-химических показателей вод, как водородный показатель (рН), окислительно-восстановительный потенциал (Eh), растворенный кислород, плотность, общее солесодержание (TDS). Комплексирование в одном анализаторе кондуктометра, рефрактометра и денсиметра может существенно расширить его аналитические возможности.

Минеральный состав вод по основным ионам $\mathrm{Ca}^{2+}, \mathrm{Na}^{+} / \mathrm{K}^{+}$, $\mathrm{Mg}^{2+}, \mathrm{HCO}_{3}^{-}, \mathrm{SO}_{4}^{2-}, \mathrm{Cl}^{-}$широко используется для выяснения генезиса поверхностных, морских, океанических и подземных вод, для определения типа вод в рамках различных классификаций (Пальмер, Сулин, Алекин и др. [9-12]), в мониторинге состояния нефтегазовых месторождений с целью контроля изменений гидрохимического фона в ходе их разработки.

На долю шести основных ионов приходится, как правило, до 95-98\% эквивалент-процентов всех ионов природных вод [12]. Информацию о ионном составе можно использовать в "бестрассерном" методе установления гидродинамических связей между нагнетательными и добывающими скважинами, в котором в качестве трассеров выступают естественные компоненты природных/пластовых вод.

\section{ЭКСПЕРИМЕНТАЛЬНАЯ ЧАСТЬ}

Объекты исследований. В качестве объекта исследования использовали образцы природных вод или их модели, приготовленные на основе литературных данных об ионном составе.

Материалы и реактивы. Приготовление моделей вод проводили с использованием солей: натрий хлористый, хч 
(ГОСТ 4233-77), натрий сернокислый 6/ в, чда (ГОСТ 4166-76); натрий углекислый кислый, чда (ГОСТ 4201-79); кальций хлористый б/в гранулированный, ч (ГОСТ 4460-79); магний сернокислый 7-водный, хч (ГОСТ 4523-77); магний хлористый 6-водный, чда (ГОСТ 4209-77); калий хлористый, хч (ГОСТ 4234-77) с учетом массы кристаллизационной воды в кристаллогидратах.

Измерения показателя преломления $n_{D}^{20}$ проводили на лабораторном рефрактометре ИРФ-454Б2М и рефрактомеTpe PEN-RI (Атаго, Япония) при $20^{\circ} \mathrm{C}$.

Электропроводность $\varkappa^{20}$ измеряли при $20^{\circ} \mathrm{C}$ кондуктометром AZ-8306 (Китай), калиброванным по методике [13].

Плотность $d^{20}$ при приготовлении моделей природных вод определяли при $20^{\circ} \mathrm{C}$ пикнометрически в мерных колбах объемом 100 мл.

\section{ОБСУЖДЕНИЕ}

Формирование базы данных по ионному составу вод и их аналитическим сигналам

Ранее в работах [14-20] было показано, что рефрактометрию и денсиметрию можно эффективно использовать в оценке группового состава многокомпонентных жидких смесей и основных солевых компонентов природных вод. Отличительная особенность этих методов состоит в достаточно хорошей аддитивности аналитических сигналов (показателя преломления $n_{i}$, плотности $d_{i}$ и производных от них величин - удельной рефракции Лорентца - Лоренца sR, удельной рефракции Эйкмана $s R_{E}$ [21], интерцепта рефракции Куртца RI [22]) по объемным или массовым долям компонентов.

Измерения электропроводности и плотности традиционны для аналитической химии природных вод [23]. Эти характеристики используются обычно для экспресс-оценки их общей минерализации, а удельная электропроводность дополнительно, как показано в [24], привлекается для подтверждения правильности определения ионного состава стандартными методами. Данные по показателям преломления природных вод не столь обширны $[25,26]$, хотя в последнее время и получили широкое распространение рефрактометры-солемеры.

Для разработки кондуктостохастического метода оценки ионного состава вод на основе кондуктометрии при вспомогательном привлечении рефракто-денсиметрии была сформирована база данных по 500 природным водам с широким диапазоном по составу и минерализации, в которую включали данные по ионному составу, литературные сведения об удельной электропроводности (при их наличии) и данные по аналитическим сигналам - удельной электропроводности $\mathcal{x}_{i}$, показателю преломления $\mathrm{n}_{i}$ и плотности $d_{i}$, определенным по моделям вод. Основными источниками данных по составу вод служили работы $[23,27-30]$ и публикации, ссылки на которые приведены в [31].

\section{Стохастические межионные корреляции и электропроводность}

Ионный состав природных вод определяется их генезисом, характеризующимся совокупностью контактов вод с породой меняющегося химического и физико-механического состава. С течением времени происходят изменения в результате вымывания поровых растворов и компонентов породы, ионного обмена, ионной адсорбции и пр. Легкорастворимые минералы при этом играют главную роль при формировании химического состава природных вод [12]. Однако при всей многовариантности ионный состав вод не является абсолютно случайным: установлены различные

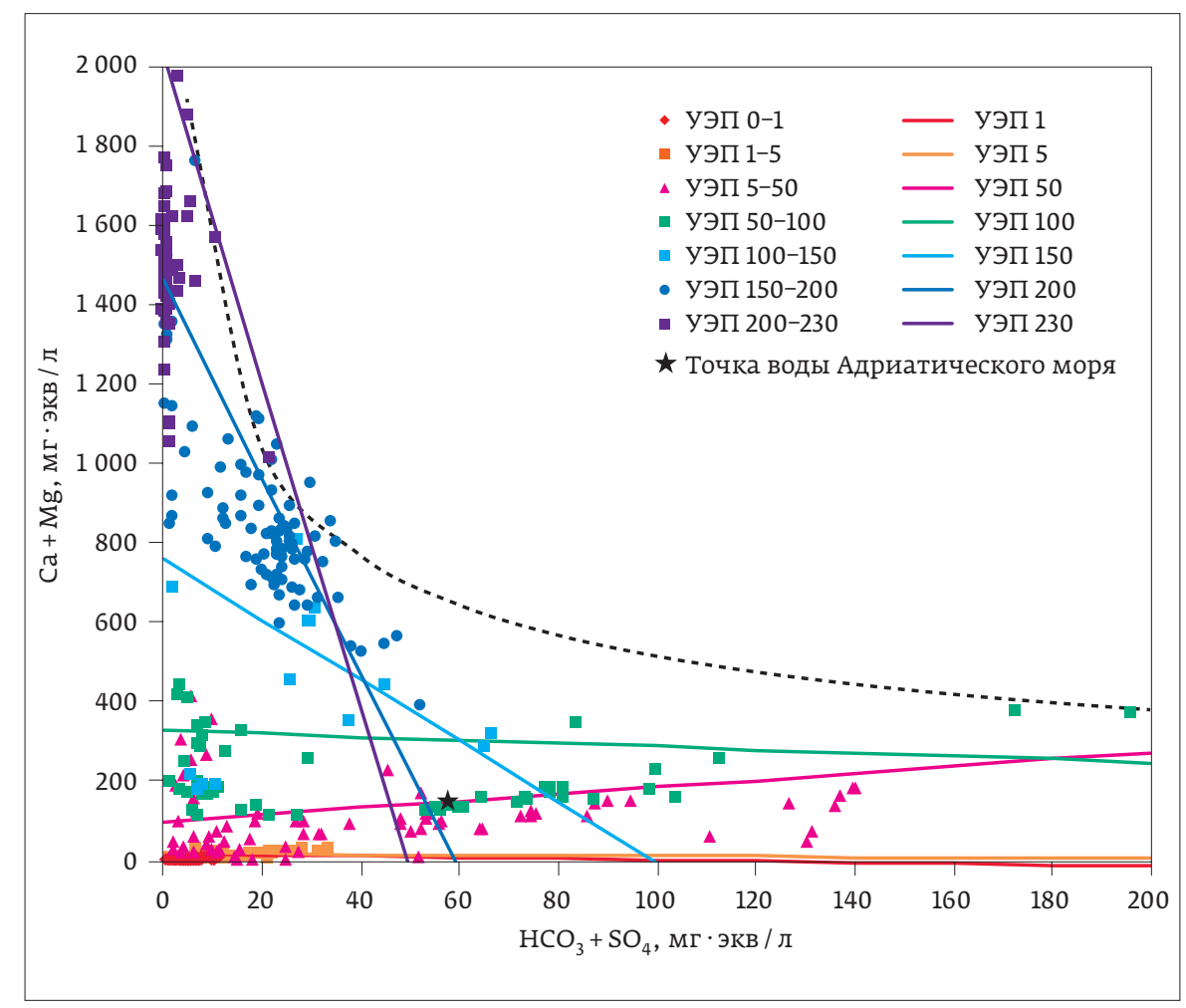

Puc. 1. Стохастическая связь между содержанием в природных водах суммы катионов кальщия и магния и суммы сульфат- и бикарбонат-анионов при вариации удельной электропроводности. Пунктирная пиния соответствует неравенству-ограничению $\left[\mathrm{Ca}^{2+}+\mathrm{Mg}^{2+}\right]<f\left(\left[\mathrm{HCO}_{3}^{-}+\mathrm{SO}_{4}^{2-}\right]\right)$. Линии электропроводности УЭП рассчитаны по верхнему пределу соответствующего интервала 


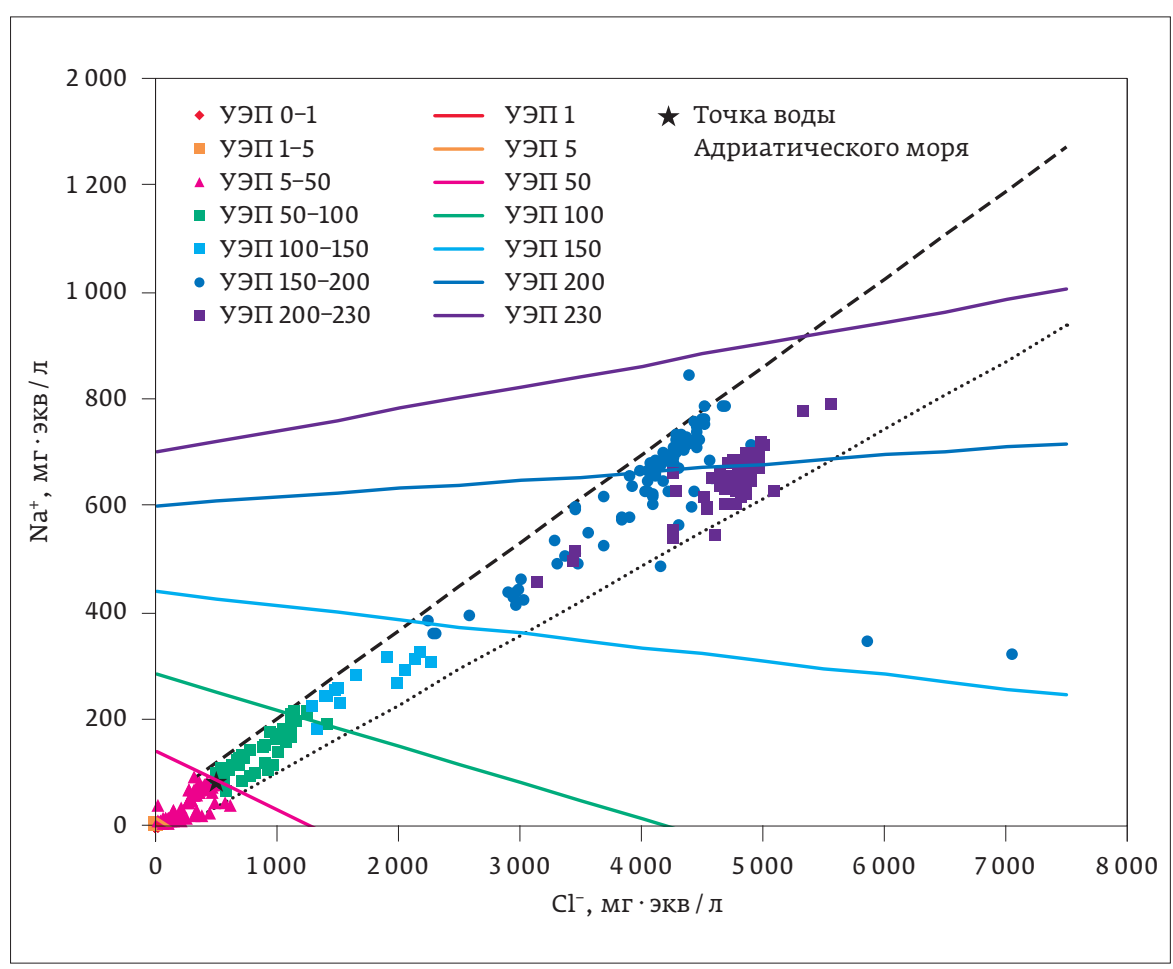

Puc. 2. Стохастическая связь содержания катиона натрия и хлорид-аниона при меняющейся удельной электропроводности УЭП. Пунктирные линии соответствуют двум неравенствам-ограничениями $\left[\mathrm{Na}^{+}\right]_{\text {MAкC }}<f_{\text {MAKC }}\left(\left[\mathrm{Cl}^{-}\right]\right)$u $\left[\mathrm{Na}^{+}\right]_{\text {Mин }}>f_{\text {MиH }}\left(\left[\mathrm{Cl}^{-}\right]\right)$

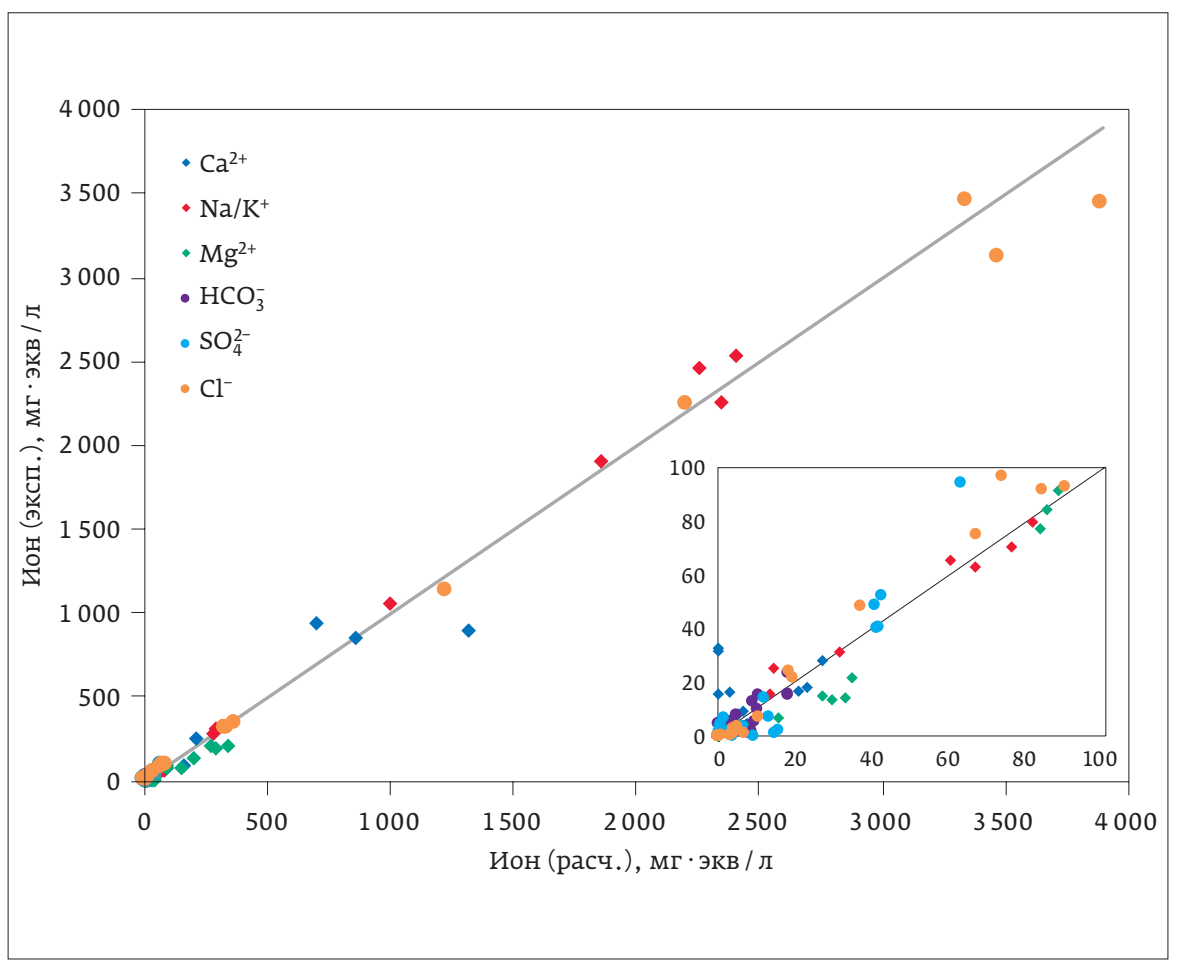

Puc. 3. Соответствие расчетных значений содержания основных ионов природных вод (25 образцов) экспериментапьным данным из питературных источников $[23,27-29,37]$ межионные и ионно-групповые корреляции. Для их установления обычно используется многомерный факторный анализ, в частности, метод главных компонент [32-34]. Исходя из цели настоящей работы в корреляционные взаимосвязи между содержанием отдельных пар ионов дополнительно введена удельная электропроводность. Это позволило перейти от использованных ранее нежестких односторонних неравенств-ограничений вида $\left[\right.$ Ион $\left._{1}^{\mathrm{n} \pm}\right]<f\left(\left[\right.\right.$ Ион $\left.\left._{2}^{\mathrm{m} \pm}\right]\right)$ к стохастическим уравнениям, отражающим парную взаимосвязь при меняющейся удельной электропроводности, общего вида $\left[\right.$ Ион $\left._{1}^{\mathrm{n}}\right]=f\left(\left[\mathrm{Ион}_{2}^{\mathrm{m} \pm}\right], \varkappa\right)$. В результате обработки данных (программа StatgraphicsPlus) получено 15 корреляционных уравнений, включающих электропроводность, для следующих пар ионов и ионных групп: $\mathrm{Ca}^{2+} / \mathrm{SO}_{4}^{2-} ; \mathrm{Ca}^{2+} / \mathrm{HCO}_{3}^{-} ; \mathrm{Mg}^{2+} / \mathrm{HCO}_{3}^{-}$; $\mathrm{Cl}^{-} / \mathrm{HCO}_{3}^{-} ; \mathrm{Na}^{+} / \mathrm{HCO}_{3}^{-} ; \mathrm{Mg}^{2+} / \mathrm{SO}_{4}^{2-}$; $\mathrm{Na}^{+} / \mathrm{Cl}^{-} ; \mathrm{Na}^{+} / \mathrm{SO}_{4}^{2-} ; \mathrm{Ca}^{2+} / \mathrm{Cl}^{-} ; \mathrm{Ca}^{2+} / \mathrm{Na}^{+}$; $\mathrm{Cl}^{-} / \mathrm{SO}_{4}^{2-} ; \mathrm{Mg}^{2+} / \mathrm{Na}^{+} ; \mathrm{Mg}^{2+} / \mathrm{Ca}^{2+} ; \mathrm{Mg}^{2+} / \mathrm{Cl}^{-}$; $\left(\mathrm{Ca}^{2+}+\mathrm{Mg}^{2+}\right) /\left(\mathrm{HCO}_{3}^{-}+\mathrm{SO}_{4}^{2-}\right)$.

Графические примеры двух из 15 стохастических межионных взаимосвязей и удельной электропроводности (УэП) с использованием данных для 500 природных вод показаны на рис. 1 и 2. На них же в качестве примера (из 500 образцов) продемонстрировано положение точки воды Адриатического моря [35], использованной для иллюстрации результатов расчета.

\section{Кондукто-стохастический} подход к оценке содержания основных ионов

Для оценки основных ионных компонентов вод использована стохастическая информация (15 уравнений парной ионной взаимосвязи, характеризующихся своими стандартными отклонениями $S_{i}$ ) и удельная электропроводность. В качестве дополнительных уравнений и неравенствограничений при поиске решения применяли уравнения зарядового баланса и корреляционное уравнение, 
по которому на основе экспериментальной удельной электропроводности воды $\chi$ (мСм/см) рассчитывали общую минерализацию (мг·экв/л), содержание хлорид-иона, а также ограничение на не отрицательность получаемого результата. Поиск решения по ионному составу проводили методом взвешенных наименьших квадратов в Excel. В качестве первого приближения использовали нулевые значения искомого решения. При поиске решения минимизировали параметр $\theta$, который рассчитывали по соотношению:

$$
\begin{aligned}
& \theta=\sum_{(\mathrm{k}=1)}^{15}\left(\left([\text { Ион1 }]_{\text {расч. }}-f\left([\text { Ион2 }]_{\text {расч. }} ; \varkappa_{\text {эксп. }}\right)\right) / S_{\mathrm{k}}\right)^{2}+ \\
& +\left(\left(\left[\mathrm{Cl}^{-}\right]_{\text {расч. }}-f\left(\varkappa_{\text {эксп. }}\right)\right) / s_{\mathrm{Cl}}\right)^{2}+ \\
& +\left(\left(\left[\mathrm{Ca}^{2+}\right]_{\text {pacч. }}+\left[\mathrm{Mg}^{2+}\right]_{\text {paсч. }}+\left[\mathrm{Na}^{+} / \mathrm{K}^{+}\right]_{\text {pacч. }}\right)-\right. \\
& \left.-\left(\left[\mathrm{Cl}^{-}\right]_{\text {pacч. }}+\left[\mathrm{SO}_{4}^{2-}\right]_{\text {pacч. }}+\left[\mathrm{HCO}_{3}^{-}\right]_{\text {pacч. }}\right)\right)^{2}+ \\
& +\left(\left(\left(\left[\mathrm{Ca}^{2+}\right]_{\text {расч. }}+\left[\mathrm{Mg}^{2+}\right]_{\text {расч. }}+\left[\mathrm{Na}^{+} / \mathrm{K}^{+}\right]_{\text {расч. }}\right)-\right.\right. \\
& \left.\left.-f\left(\varkappa_{\text {эксп. }}\right)\right) / S_{\text {Гкат }}\right)^{2} \text {. }
\end{aligned}
$$

где [Ион1 $]_{\text {kрасч, }}[\text { Ион2 }]_{\text {kрасч. }}$ - расчетные/ текущие концентрации ионов 1 и 2 для корреляционного $k$-уравнения, мг·экв/л,

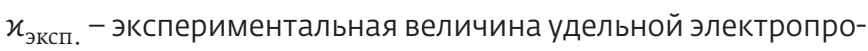
водности, мСм / см (20 ㄷ), $S_{k}$ - среднеквадратичная погрешность $k$-той корреляции. Разности стохастических уравнений (невязки) нормировались среднеквадратичными погрешностями $S_{k}$ соответствующих уравнений тройной (с электропроводностью) взаимосвязи. Для первого приближения при поиске решения строку ионов (мг·экв/л) (6 изменяемых ячеек) программы Ехсеl оставляли пустой. На рис. 3 проведено сравнение расчетных и экспериментальных данных по содержанию ионов в водах, определенных другими аналитическими методами [23, 27-29, 31].

Из рис. 3 можно видеть, что отклонения расчетного содержания ионов по кондукто-стохастическому методу от данных по ионному составу минимальны для натрий-иона и хлорид-иона, для остальных четырех ионов эти отклонения несколько выше и примерно равновелики. Изменение относительной погрешности оценки содержания ионов кондукто-стохастическим методом от минерализации природной воды показаны на рис. 4. Погрешность определения содержания ионов (мгхэкв / л) нормировали относительно общей минерализации (мгхэкв / л) и рассчитывали по уравнению:

$$
\delta, \%=200 \cdot \sqrt{\left(\left[\text { Ион }^{ \pm}\right]_{i, \text { расч. }}-\left[\text { Ион }^{ \pm}\right]_{i, \text { эксп. }}\right)^{2}} / \sum_{i=1}^{6}\left[\text { Ион }^{ \pm}\right]_{i, \text { эксп. }} .
$$

\section{Оценка ионного состава природных вод}

Для оценки принадлежности исследуемого образца воды к природным водам и возможности оценки ионного состава кондукто-стохастическим методом использовали рефракто- и денсиметрию, а именно, идентификационный полярный угол $\varphi_{\text {IPA }}$ образца, рассчитываемый на основе его показателя преломления и плотности по алгоритму, описанному в [18]. В случае, если $\varphi_{\text {IPA }}$ выходит за пределы интервала $-170^{\circ}<\varphi_{\text {IPA }}<-142^{\circ}$, то исследуемый образец не является естественной природной водой и содержит, по-видимому, посторонние органические примеси. В этом случае применение кондукто-стохастического метода невозможно, поскольку используемые в нем межионные стохастические корреляции устанавливались для естественных природных вод, не содержащих техногенные примеси различной природы. Ниже приведена диаграмма соответствия ионного состава воды (экв. \%) Адриатического моря, приведенного в литературе, и рассчитанного нами ионного состава.

\section{ЗАКЛЮЧЕНИЕ}

Предложен кондукто-стохастический экспресс-метод оценки ионного состава природных вод с минерализацией более 5 г / л на основе решения системы из 15 стохастических уравнений, полученных с помощью корреляционного анализа парных межионных взаимосвязей для 500 образцов

Puc. 4. Зависимость относительной погрешности $(d, \%)$ определения содержания ионов от минерализащии природных вод 


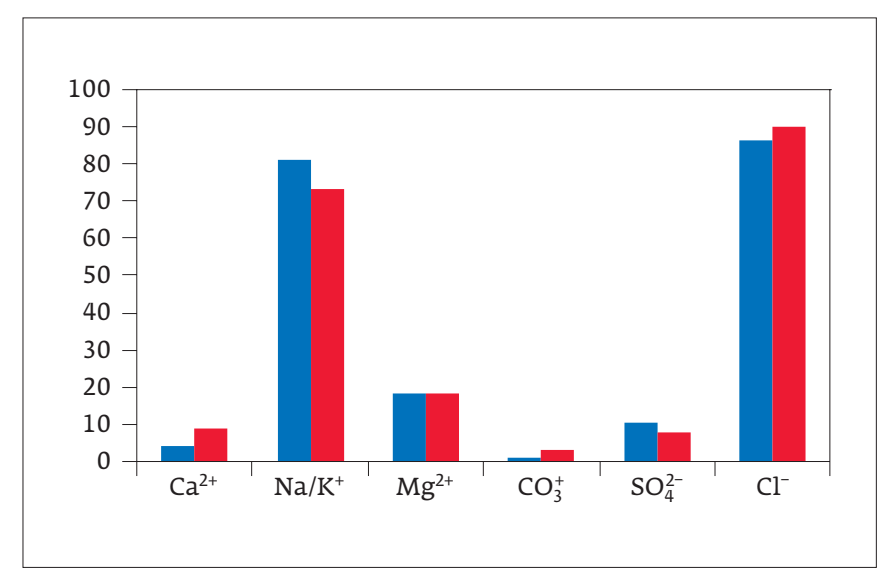

Puc. 5. Диаграмма ионного состава (экв\%) воды Адриатического моря (синие столбцы) и рассчитанного нами состава с использованием данных по удельной электропроводности (красные столбцы)

природных вод как функций удельной электропроводности. Чем выше минерализация вод, тем меньше относительная ошибка определения ионного состава.

Дополнительное оснащение портативных средств контроля ионного состава вод рефрактометрическим и денсиметрическим устройствами позволит определять принадлежность исследуемого образца к естественным природным водам или к сточным. Алгоритм экспресс-метода оценки состава природных вод в перспективе может быть использован в качестве методического обеспечения к портативным гидрохимическим анализаторам, мониторинговым буям и глубинным зондам.

Авторы выражают искреннюю признательность профессору кафедры аналитической химии Казанского (Приволжского) федерального университета Будникову Г. К. за ценные советы при обсуждении статьи.

\section{ЛИТЕРАТУРА}

1. ГОСТ Р 54316-2011. Воды минеральные природные питьевые. Общие технические условия. - М.: ФГУП "Стандартинформ", 2011. 45 с.

2. ГОСТ 24902-81. Вода хозяйственно-питьевого назначения. Общие требования к полевым методам анализа. М.: ФГУП "Стандартинформ", 2010. 3 С.

3. Катаева М. А., Тиунова М. Ю. Комплексный подход кгидрохимическому анализу попутных вод Уренгойского нефтегазоконденсатного месторождения // Экспозиция Нефть Газ. 2015. Т. 4. № 43. С. 44-47.

4. Кошелев А. В., Ли Г.С., Катаева М. А. Оперативный гидрохимический контроль за обводнением пластовыми водами объектов разработки Уренгойского нефтегазоконденсатного месторождения: Тез. докл // Научно-технический сборник Вести газовой науки. Проблемы ресурсного обеспечения газодобывающих регионов России. - СПб, 2014. № 3 (19). С. 106-115.

5. Порфирьева А. В., Зиятдинова Г. К., Медянцева Э.П. и др. Гидрохимический анализ: учеб. пособие. - Казань: Изд-во Казан. ун-та, 2018. 88 с.

6. РД 52.24.403-2007. Массовая концентрация кальция в водах. Методика выполнения измерений титриметрическим методом с трилоном Б. - Ростов-на-Дону: "Росгидромет», 2007. 31 с.
7. ГОСТ 4245-72. Вода питьевая. Методы определения содержания хлоридов. - М.: "Гос. станд. СССР ВНИИПО", 2009. 5 с.

8. Муравьев А.Г. Руководство по определению показателей качества воды полевыми методами / 3-е изд. - СПб: Крисмас, 2009. 218 с.

9. Palmer C.C. The geochemical interpretation of water analysis. Government printing office, Washington. 1911. 31 p.

10. Сулин В.А. Воды нефтяных месторождений в системе природных вод. - М.: Гостоптехиздат, 1946. 95 с.

11. Сулин В.А. Условия образования, основы классификации и состав природных вод. - М.: АН СССР, 1948.105 с.

12. Самарина В.С. Гидрогеохимия. Учеб. пос. - Л.: Изд. ЛГУ, 1977. 360 С.

13. Абросимов В. К., Королев В. В., Афанасьев В. Н. и др. Экспериментальные методы химии растворов: Денсиметрия, вискозиметрия, кондуктометрия и другие методы. - М.: Наука, 1997. 351 C

14. Николаев В.Ф. Экспресс-методы тестирования композиционных продуктов нефтепромысловой химии и моторных топлив: монография. - Казань: Казан. нац. исслед. технол. ун-т, 2012. 124 с.

15. Nikolaev V. F., Penkovsky A. I., Tabrisov I. I., Sultanova R. B. Express method for total content assessment of aromatic hydrocarbons and oxygen in finished gasolines by refractometry and densimetry / Fuel. 2015. V. 142. Р. 94-101.

16. Свид. о гос. рег. прогр. для ЭВМ. Euroxtest. Николаев В. Ф. (RU). № 2014660852; поступ. 07.07.14; гос. рег. 16.10.14.

17. Разработка метода мониторинга технологических процессов нефтепереработки, нефтехимии и органического синтеза с визуализацией траекторий процессов на 2D-идентификационных картах по химико-аналитической информации о групповом составе продуктов, получаемой на основе комплексирования методов рефракто- и денсиметрии / Грант РФФИ № 18-47-160008 p_a. Николаев В. Ф., Казан. нац. исслед. технол. ун-т, Казань, 2018.

18. Nikolaev V. F., Timirgalieva A. Kh., Barskaya E. E. et al. Hydrogeochemistry: natural waters in full view // Вестн. Казан. технол. ун-та. 2016. Т. 19. № 3. С. 5-10.

19. Николаев В.Ф., Сулайман Б.Ф., Тимиргалиева А. Х. и др. Алгоритмы анализа группового состава и визуальной идентификации технических жидкостей, моторных топлив и природных вод для портативных экспресс-анализаторов и смартфонов с рефрактометрическим и денсиметрическим сенсорами // Сб. мат. Науч.-практ. конф. "Научное приборостроение-современное состояние и перспективы развития". - М.: Богородский печатник, 2016. С. 112-113.

20. Николаев В.Ф., Булыгин Д. В. Экспресс-метод оценки минерального состава закачиваемых и попутных вод нефтяных месторождений // Нефть. Газ. Новации. 2018. № 4. С. 56-60.

21. Иоффе Б. В. Рефрактометрические методы химии / 2-е изд. Л.: Химия, 1974. 400 с.

22. Куртц С. С. В Кн.: Химия углеводородов нефти / Под ред. Б. Т. Брукса, С. Э. Бурда, С. С. Куртца, Л. Шмерлинга. - М.: ГНТИНГТЛ, 1958. Т. 1. C. $227-277(553$ с.).

23. Воробьев Н.И. Применение измерения электропроводности для характеристики химического состава природных вод. M.: AH CCCP, 1963. 144 C.

24. Rossum J. R. Conductance Method for Cheking Accuracy of Water Analyses // J. Analyt. Chem. 1949. V. 21. № 5. P. 631-631.

25. The Index of Refraction of Seawater / SIO Ref. 76-1; Grant № N66857-73-C-0146. Austin Roswell W., Halikas George.Univ.of California, San Diego., 1976. 121 p.

26. Tengesdal $\varnothing$. A. Measurement of seawater refractive index and salinity by means of optical refraction: A thesis of the Deg. Master Sci. Depart. Phys. and Technol. Univ. of Bergen, 2012. 134 p.

27. Harbison J. E. Groundwater chemistry and hydrological processes within a quaternary coastal plain: pimpama, southeast queensland: A thesis of the Deg. of PhD: Queensland Univ. of Tech., 2007. 278 p.

28. Suryawanshi R.A., Desai R. V., Golekar R. B. Geochemical Characteristics of Groundwater from Urmodi River Basin, SataraDisrict Maharashtra, India // Int. Res. J. of Earth Sci. 2016. V. 4. № 2. P. 31-41.

29. Хисамов Р.С., Гатиятуллин Р. Н., Ибрагимов Р. Л. и др. Гидрогеологические условия месторождений тяжелых высоковязких нефтей и природных битумов / Науч. ред. Р. С. Хисамов. Казань: Ихлас, 2016. 176 с. 
30. [Электронный ресурс]: http://tehtab.ru/guide/guidemedias/ guidewater/apprwaterriversectrf // сайт "TehTab" Технич. табл. (дата обращения: 05.05.2019).

31. Николаев В.Ф., Фосс Л.Е., Сулайман Б.Ф. и др. Унифицированная шкала природных вод // Георесурсы / Georesources. 2018. Т. 20. № 2. C. 58-66

32. Zhang, Y., Xu, M., Li, X., Qi, J., Zhang, Q., Guo, J., Leilei Y \& Zhao, R. Hydrochemical Characteristics and Multivariate Statistical Analysis of Natural Water System: A Case Study in Kangding County, Southwestern China // J. Water. 2018. V. 10. P. 80.

33. Ravikumar P., Somashekar R. K. Principal component analysis and hydrochemicalfacies characterization to evaluate groundwater quality in Varahi river basin, Karnataka state, India // J. Appl. Water Sci. 2017. V. 7. № 2. P. 745-755.

34. Manoj K., Ghosh S., Padhy P. K. Characterization and Classification of Hydrochemistry using Multivariate Graphical and Hydrostatistical Techniques // Res. J. of Chem. Sci. 2013. V. 3. № 5. P. 32-42.

35. Mollema P., Antonellini M., Dinelli E. et al. The influence of flow-through saline gravel pit lakes on the hydrologic budget and hydrochemistry of a Mediterranean drainage basin // J. Limnol. Oceanogr. 2015. V.60. P. 2009-2025.

\section{REFERENCES}

1. GOST R54316-2011. Drinking Natural Mineral Waters. General Specification. Moscow, Standartinform Publ., 2011, 45 p.

2. GOST 24902-81. Housekeeping and Potable Water. General Requirements for Field Methods of Analysis. Moscow, Standartinform Publ, 2010, 3 p.

3. Kataeva M. A., Tiunova M. Yu. An Integrated Approach to Hydrochemical Analysis of Associated Waters of the Urengoy Oil and Gas Condensate Field. Ekspoziciya Neft' Gaz - Oil Gas Exposition. 2015, v. 4 , no. 43, pp. 44-47.

4. Koshelev A. V., Li G. S., Kataeva M. A. Operational Hydrochemical Monitoring of Formation Watering at Development Sites of the Urengoy Oil and Gas Condensate Field: Abstracts. Scientific and Technical Collection News of Gas Science. Problems of Resource Support of Gas Producing Regions of Russia. Saint Petersburg, 2014, no. 3 (19), pp. 106-115.

5. Porfir'eva A.V., Ziyatdinova G. K., Medyantseva E. P. et al. Hydrochemical analysis. Kazan, Publishing house of Kazan University, 2018, 88 p.

6. RD52.24.403-2007. Mass Concentration of Calcium in Water. Measurement Procedure by the Titrimetric Method with Trilon B. Rostov-on-Don, Rosgidromet Publ., 2007, 31 p.

7. GOST 4245-72. Drinking water. Methods for determination of chloride content. Moscow, USSR State Standard VNIIPO Publ., 2009, 5 p.

8. Murav'ev A. G. Guidelines for determining water quality indicators using field methods. $3^{\text {rd }}$ edition, Saint Petersburg, Krismas Publ., 2009, $218 \mathrm{p}$.

9. Palmer C. C. The geochemical interpretation of water analysis. Washington, Governmentprintingoffice Publ., 1911, 31 p.

10. Sulin V. A. Water Oil Fields in the Natural Water System. Moscow, Gostoptekhizdat Publ., 1946, 95 p.

11. Sulin V.A. Formation conditions, the basics of classification and composition of natural waters. Moscow, USSR Academy of Sciences Publ., 1948, $105 \mathrm{p}$

12. Samarina V.S. Hydrogeochemistry. Leningrad, Leningrad State University Publ., 1977, 360 p.

13. Abrosimov V.K., Korolev V.V., Afanas'ev V.N. et al. Experimental Methods of Solution Chemistry: Densimetry, Viscometry, Conductometry and Other Methods. Moscow, Nauka Publ., 1997, $351 \mathrm{p}$.

14. Nikolaev V. F. Express Methods for Testing Composite Products of Oilfield Chemistry and Motor Fuels. Kazan, Kazan National Research Technological University Publ., 2012, 124 p.

15. Nikolaev V. F., Penkovsky A. I., Tabrisov I. I. et al. Express Method for Total Content Assessment of Aromatic Hydrocarbons and Oxygen in Finished Gasolines by Refractometry and Densimetry // Fuel, 2015, v. 142, pp. 94-101.
16. Nikolaev V.F. Certificate of state registration of a computer program. Euroxtest. N2014660852 (RU), received 07.07.14, state registration 16.10.14

17. Nikolaev V.F. Development of a Method for Monitoring Technological Processes of Oil Refining, Petrochemistry and Organic Synthesis with Visualization of Process Trajectories on 2D Identification Cards using Chemical-analytical Information on the Group Composition of Products Obtained by Combining Refractometry and Densimetry Methods, RFBR grant N18-47-160008, Kazan National Research Technological University, Kazan, 2018

18. Nikolaev V. F., Timirgalieva A. Kh., Barskaya E. E. et al. Hydrogeochemistry: natural waters in full view. Vestn. Kazan. tekhnol. un-ta. - Bulletin of Kazan Technological University, 2016. v. 19, no. 3, pp. 5-10.

19. Nikolaev V. F., Sulaiman B. F., Timirgalieva A. Kh. et al. Algorithms for the Analysis of Group Composition and Visual Identification of Technical Fluids, Motor Fuels and Natural Waters for Portable Express Analyzers and Smartphones with Refractometric and Densimetric Sensors. Scientific conf. Scientific Instrumentation - Current State and Development Prospects, Collection of materials, Moscow, Bogorodskii pechatnik Publ., 2016, pp. 112-113.

20. Nikolaev V.F., Bulygin D. V. Express method for assessing the mineral composition of injected and associated water in oil fields. Neft' .Gaz. Novatsii - Oil. Gas. Novation, 2018, no. 4, pp. 56-60.

21. Ioffe B. V. Refractometric chemistry methods. 2nd ed., Leningrad, Khimiya Publ., 1974, 400 p.

22. Kurtz S. S. in Book: Chemistry of Petroleum Hydrocarbons / Ed. B. T. Bruks, S. E. Burda, S. S. Kurtz, L. Shmerling, Moscow, GNTINGTL Publ., 1958, v. 1, pp. 227-277 (553 p.).

23. Vorob'ev N. I. The Use of Conductivity Measurements to Characterize the Chemical Composition of Natural Waters. Moscow, USSR Academy of Sciences Publ., 1963, 144 p.

24. Rossum J. R. Conductance Method for Cheking Accuracy of Water Analyses. J. Analyt. Chem. 1949, v. 21, no. 5, pp. 631-631.

25. The Index of Refraction of Seawater / SIO Ref. 76-1; Grant № N66857-73-C-0146. Austin Roswell W., Halikas George. Univ.of California, San Diego., 1976, $121 \mathrm{p}$

26. Tengesdal Ø. A. Measurement of Seawater Refractive Index and Salinity by Means of Optical Refraction: A Thesis of the Deg. Master Sci. Depart. Phys. and Technol. Univ. of Bergen, 2012, 134 p.

27. Harbison J. E. Groundwater Chemistry and Hydrological Processes within a Quaternary Coastal Plain: Pimpama, Southeast Queensland A Thesis of the Deg. of PhD: Queensland Univ. of Tech., 2007, 278 p.

28. Suryawanshi R. A., Desai R. V., Golekar R. B. Geochemical Characteristics of Groundwater from Urmodi River Basin, Satara Disrict Maharashtra, India. Int. Res. J. of Earth Sci. 2016, v. 4, no. 2, pp. 31-41.

29. Hisamov R. S., Gatiyatullin R. N., Ibragimov R. L. et al. Hydrogeological Conditions of Deposits of Heavy High-Viscosity Oils and Natural Bitumen. Sci. Ed. R. S. Khisamov. Kazan, Ihlas Publ., 2016, 176 p.

30. Website TehTab - Technical Tables. Available at: http://tehtab.ru/ guide/guidemedias/guidewater/apprwaterriversectrf/ (date of the application: 05.05.2019).

31. Nikolaev V. F., Foss L. E., Sulaiman B. F. et al. The Unifed Scale of Natural Waters. Georesursy-Georesources, 2018, v. 20, no. 2, p. 58-66

32. Zhang Yu., Xu M., Li X. et al. Hydrochemical Characteristics and Multivariate Statistical Analysis of Natural Water System: A Case Study in Kangding County. Southwestern China Water, 2018, v. 10, no. 1, 80 p (pp. 1-17).

33. Ravikumar P., Somashekar R. K. Principal Component Analysis and Hydrochemicalfacies Characterization to Evaluate Groundwater Quality in Varahi River Basin, Karnataka State, India. J. Appl. Water Sci., 2017, v. 7, no. 2, pp. 745-755.

34. Manoj K., Ghosh S. Padhy P. K. Characterization and Classification of Hydrochemistry using Multivariate Graphical and Hydrostatistical Techniques. Res. J. of Chem. Sci. 2013. v.3, no. 5, pp. 32-42.

35. Mollema P., Antonellini M., Dinelli E. et al. The Influence of Flow-through Saline Gravel Pit Lakes on the Hydrologic Budget and Hydrochemistry of a Mediterranean Drainage Basin. J. Limnol. Oceanogr. 2015. v. 60, pp. 2009-2025. 